\title{
Treatment of migraine and tension-type headache in Croatia
}

\author{
Vlasta Vuković • Davor Plavec • \\ Arijana Lovrenčić Huzjan • Mislav Budišić • \\ Vida Demarin
}

Received: 9 September 2009/ Accepted: 6 February 2010/Published online: 6 March 2010

(c) Springer-Verlag 2010

\begin{abstract}
The aim of this study was to assess the treatment patterns of migraine and tension-type headache in the Croatian population. Analysis included the proportion of patients who were taking specific antimigraine therapy and the number of tablets per attack per month, the proportion of patients who were taking prophylactic therapy or using alternative treatment methods and their satisfaction with the treatment. The design of the study was a cross-sectional survey. Self-completed questionnaires were randomly distributed to adults $>18$ years of age in the Croatian population. A total of 616 questionnaires were analyzed: 115 patients with migraine $(\mathrm{M}), 327$ patients with tension-type headache (TTH), and 174 patients with probable migraine (PM) and TTH. Specific antimigraine therapy was taken by half of patients with migraine: $35.7 \%$ of patients used triptans and $21.7 \%$ ergotamines. Prophylactic treatment had been used by $13.9 \%$ of M, $1.2 \%$ of TTH, and $6.9 \%$ of PM patients. Alternative methods of treatment were tried by $27 \%$ of $\mathrm{M}$ and TTH patients. Only $16.8 \%$ of patients with $\mathrm{M}$ pay regular visits to physicians, while $36.3 \%$ never visited a physician. More than half of TTH patients have never visited a physician. The majority of patients are only partially satisfied with their current treatment, and almost one-third are not satisfied. Results of this study indicate that the treatment of primary headaches in Croatia should be improved.
\end{abstract}

\footnotetext{
V. Vuković $(\bowtie) \cdot$ A. Lovrenčić Huzjan · M. Budišić .

V. Demarin

University Department of Neurology, University Hospital

"Sestre milosrdnice", Vinogradska c. 29, 10000 Zagreb, Croatia

e-mail: vlasta.vukovic@uclmail.net

D. Plavec

Research Department, Children's Hospital "Srebrnjak", Zagreb, Croatia
}

Keywords Migraine - Tension-type headache . Probable migraine Acute treatment .

Prophylactic treatment

\section{Introduction}

Studies worldwide continuously show low rates of medical consultations in patients with headache, with visits to neurologists being especially low, even with those patients who are aware of their condition [1,2]. A large number of migraine patients receive no medical follow-up, think that consultations are useless and that there is no cure for their migraines [3]. Even though migraine is a significant personal and public health problem, it is not effectively managed in clinical practice. Most studies show that in the general population triptans are taken by $3-19 \%$ of patients with migraine, while most other patients are taking simple analgesics [2-6]. In some countries, higher percentages of triptan use have been observed [7]. Preventive treatment is used by a low percentage of migraine patients, with studies showing a range of $6-12.4 \%[3,8]$. The aim of this study was to assess the patterns of headache treatment in the general population, and to assess medical attendance as well as the level of satisfaction with current therapies offered. Our survey is the first of its kind in the Croatian population.

\section{Methods}

This study was part of a population-based study whose aim was to assess the prevalence of migraine $(\mathrm{M})$, probable migraine (PM) and tension-type headache (TTH) as well as patterns of health care in Croatia. The design of the study was a cross-sectional survey of an adult population sample 
using a self-completed questionnaire. The study population included adults $>18$ years of age, and the sample represented 4,437,000 Croatian adults. The survey was conducted in four Croatian cities: Zagreb, Split, Osijek, and Dubrovnik. The questionnaires were distributed in general medical practices randomly selected to contain a mix of urban, suburban, and rural settings, as well as range of social classes. In Croatia, $96 \%$ of the population is registered with a GP, providing a convenient frame for an indiscriminate sampling of the local population. Randomly selected patients from the GP's database were asked to fill out the questionnaire.

The questionnaire consisted of three sections:

Section 1 consisted of demographic data (age, gender, education, marital status, employment, and city of residence) as well as questions regarding the presence of headache.

Section 2 included questions which were designed to define the nature of the headache according to the ICHD2 [9] criteria for M, PM, and TTH.

Section 3 consisted of questions aimed to assess patterns of headache treatment:

(a) Have you ever visited a doctor because of your headaches?

(b) Which doctor(s) have you visited?

(c) Which therapy do you use for acute headache attacks (respondents were asked to make a list of specific and non-specific therapies, numbers and types of medication, and overall satisfaction with therapy)

(d) Have you ever used prophylactic therapy?

(e) Have you ever tried alternative methods of treatment?

(f) Are you satisfied with your current therapy (on the whole)?

(g) Which are the main sources from which you receive information regarding health?

The questionnaire was designed combining literary sources of similar studies, the IHS classification (second edition) and advice from epidemiologic researchers. On return, the questionnaires were checked for the completeness, and questionnaires containing more than one unanswered question from any of the four sections were excluded from the final analysis. Patients who had definite $\mathrm{M}$ and TTH were classified into the $\mathrm{M}$ group, and those who had PM and TTH were classified in the PM group. Patients with TTH only were classified into the TTH group. This classification was made because the sampling size was too small to divide the patients into more than three groups. Furthermore, studies worldwide show that most M sufferers will have also TTH, at some point in their lives.
Statistical analysis

Data analysis was performed using the STATISTICA for WINDOWS release 6.0. Continuous variables were summarized as mean and standard deviation (SD). Categorical variables were summarized as a number (\%). In the statistical analysis, the chi-square and Fisher exact tests were used to compare distribution of categorical variables between subgroups and Student $t$ test to compare continuous variables. Statistic significance was considered at $P<0.05$.

\section{Results}

Demographic characteristics

The questionnaires were sent to 2,000 inhabitants with 1,542 of them being suitable for analysis $(77.1 \%)$. Of the total 1,542 respondents, $640(41.5 \%)$ indicated that they suffer from a primary headache at least once within the span of a year. From the sample of 640 respondents, data regarding treatment patterns in the general population were assessed. Among 640 respondents, 115 (88 women, 27 men, mean age $42 \pm 14$ ) suffered from M, 327 (215 women, 112 men, mean age $41 \pm 14$ ) from TTH, and 174 (138 women, 36 men, mean age $39 \pm 14$ ) from PM with or without TTH. A majority of the respondents were married, had high school education, were employed, and resided in a city.

\section{Medical attendance}

A small percentage of patients with $\mathrm{M}$ visit a doctor regularly (16.8\%) (Table 1). A quarter of M and PM patients declared to have visited a doctor several times but with no effect. A doctor was never visited by $36.3 \%$ of $\mathrm{M}$ patients

Table 1 Medical attendance

\begin{tabular}{lcccc}
\hline $\begin{array}{l}\text { Visit to a } \\
\text { physician }\end{array}$ & $\begin{array}{c}\text { Migraine } \\
(\%)\end{array}$ & $\begin{array}{l}\text { TTH } \\
n=327 \\
(\%)\end{array}$ & $\begin{array}{l}\text { PM } \\
n=174 \\
(\%)\end{array}$ & $P$ value \\
\hline Never & $41(36.3)$ & $177(55.5)$ & $81(46.6)$ & 0.0024 \\
Once & $25(22.1)$ & $66(20.7)$ & $33(19.0)$ & 0.0024 \\
Several times & $28(24.8)$ & $42(13.2)$ & $42(24.1)$ & 0.0024 \\
Regularly & $19(16.8)$ & $34(10.7)$ & $18(10.3)$ & 0.0024 \\
Primary care & $57(49.6)$ & $139(42.5)$ & $74(42.5)$ & 0.39 \\
Neurologist & $51(44.4)$ & $53(16.2)$ & $43(24.7)$ & $<0.0001$ \\
Internal medicine & $4(3.5)$ & $12(3.7)$ & $8(4.6)$ & 0.85 \\
Other specialist & $10(8.7)$ & $32(9.8)$ & $17(9.8)$ & 0.26 \\
\hline
\end{tabular}

Numbers in parenthesis are percentages 
and $46.6 \%$ of PM patients, whereas more than half of patients $(55.5 \%)$ with TTH have never visited a doctor $(P=0.002)$. Approximately one-fifth of patients in all three groups visited a doctor once.

Patients with $\mathrm{M}$ have visited a neurologist significantly more as compared with TTH patients (44.4 vs. 16.2\%) $(P<0.0001)$ (Table 1$)$. Almost half of patients with any type of primary headache have visited a primary care physician at least once. Other specialists that headache sufferers visited were internal medicine doctors (24 cases), ophthalmologists (12), ENT specialists (19), rheumatologists (14), psychiatrists (9), cardiologists (2), gynecologists (2), and urologists (1).

\section{Treatment patterns}

Medication used, number of tablets taken, overall satisfaction, preventive and alternative therapies are shown in Table 2. A total of $57.4 \%$ of respondents with $\mathrm{M}$ stated that they are using specific antimigraine therapy such as triptans (sumatriptan or zolmitriptan; 35.6\%) or ergotamines $(21.8 \%)$.

Among M patients, $67.4 \%$ stated that these medications relieve the pain if taken in time and will partially help in $27.9 \%$ of cases.

Patients with $\mathrm{M}$ were least likely to take only one tablet for a headache attack as compared with the TTH and PM groups ( $P=0.0033$ ). The least-satisfied group of patients was the PM group if they took only one tablet per attack $(P=0.0001)$.

Two medications per headache attack were most likely to be taken by patients in the PM group $(P=0.003)$. Most satisfied with two tablets were patients from the TTH group $(P=0.004)$. Two or three tablets per headache attack were most likely to be taken by patients in the $\mathrm{M}$ and PM groups as compared with the TTH group $(P=0.003)$. Regarding satisfaction with therapy, there was no significant difference among patient groups if they had to use three tablets per attack. Comparing all three groups, patients with $\mathrm{M}$ were most likely to take the largest total number of medications for their headache attacks per month.

Prophylactic treatment has been prescribed to $13.9 \%$ of M, $1.2 \%$ of TTH, and $6.9 \%$ of PM patients. Details on the type of prophylactic therapy used were not obtained.

Alternative methods for headache treatment were used by $27 \%$ of $\mathrm{M}$ and TTH patients; $60 \%$ of TTH patients were satisfied with therapies received as were approximately $40 \%$ of patients with $\mathrm{M}$ and PM. There was no statistical significance among the number of patients who used alternative treatment between the three groups of patients $(P>0.05)$ (Table 2).
Satisfaction with therapy

Satisfaction with current therapies among our group of patients was not statistically different between subgroups (Table 3). Approximately one quarter of patients or less declared they were completely satisfied, nearly half of the patients were partially satisfied, one-fifth (M and TTH groups) of patients were mostly unsatisfied and $10 \%$ or less in each group were not satisfied at all (Table 3).

\section{Sources of health information}

As an information source, patients with $\mathrm{M}$ and PM were more likely to visit a specialist such as a neurologist or internal medicine specialist $(P=0.005)$, and gain information regarding headaches from internet $(P=0.002)$ or medical books $(P=0.0008)$ as compared with patients with TTH. Patients with TTH are more likely to gain information from family and friends $(P=0.02)$ or mass media $(P=0.0001)$ as compared with $\mathrm{M}$ patients (Table 4).

\section{Discussion}

\section{Medical attendance}

Worldwide population-based epidemiologic surveys have consistently demonstrated that the majority of $\mathrm{M}$ sufferers are not currently consulting their physicians about their problem and that many have never even consulted a physician [10-18].

Studies in Canada, Denmark, The Netherlands, and USA have shown that $55-70 \%$ of $\mathrm{M}$ patients sought initial treatment from primary care physicians [10, 12, 15]. A UK study showed that $20 \%$ of $\mathrm{M}$ sufferers never visited a doctor and among those who did almost $50 \%$ felt that the physician did not help [13]. In Sweden, $27 \%$ of patients with $\mathrm{M}$ visited a doctor (6\% regularly and $21 \%$ occasionally) with $60 \%$ being satisfied with their treatment [16]. In Austria, $39.6 \%$ never visited a doctor, $30.8 \%$ once, $16.8 \%$ occasionally, and $12.8 \%$ regularly [18]. Two studies from France indicated that $59 \%$ had visited a doctor; in one study $70 \%$ were not satisfied with initial treatment after their first visit, with $48 \%$ being satisfied in the other study. Among those who had never visited a doctor $87 \%$ were from MIDAS I group and even $68 \%$ were from MIDAS IV group [3, 19]. A study that encompassed data from six South American countries stated that $59 \%$ of patients had never visited a doctor [20]. In Europe, patients usually need to be referred to a specialist by their primary care physician, and about 5-15\% will visit a specialist [15, 21, 22]. 
Table 2 Use of specific, non-specific, prophylactic, and alternative therapies in patients with headache, their overall satisfaction, and number of tablets taken according to headache subtype

\begin{tabular}{|c|c|c|c|c|}
\hline Medications & $\begin{array}{l}\text { Migraine } \\
n=115(\%)\end{array}$ & $\begin{array}{l}\text { TTH } \\
n=327(\%)\end{array}$ & $\begin{array}{l}\text { PM } \\
n=174(\%)\end{array}$ & $P$ value \\
\hline \multicolumn{5}{|l|}{ Specific } \\
\hline Sumatriptan & $23(20.0)$ & $1(0.3)$ & $17(9.8)$ & $<0.0001$ \\
\hline Zolmitriptan & $18(15.7)$ & $2(0.6)$ & $7(4.0)$ & $<0.0001$ \\
\hline Ergotamines & $18(15.7)$ & $3(0.9)$ & $14(8.1)$ & $<0.0001$ \\
\hline Dihydroergotamines & $7(6.1)$ & 0 & $4(2.3)$ & 0.0001 \\
\hline \multicolumn{5}{|l|}{ Do these medications relief pain? } \\
\hline Yes, if taken on time & $29(67.4)$ & $1(16.7)$ & $14(50.0)$ & 0.0007 \\
\hline Partially & $12(27.9)$ & $2(33.3)$ & $13(46.4)$ & 0.0007 \\
\hline No & $2(4.7)$ & $3(50.0)$ & $1(3.6)$ & 0.0007 \\
\hline \multicolumn{5}{|c|}{ Number of tablets (specific or non-specific) } \\
\hline Per attack: one & $84(73.0)$ & $296(90.5)$ & $149(84.2)$ & 0.0033 \\
\hline Tablets per month, number (range) ${ }^{\mathrm{a}}$ & $8.6(4.9-12.2)$ & $5.3(4.2-6.4)$ & $7.3(5.4-9.1)$ & 0.0420 \\
\hline \multicolumn{5}{|l|}{ Do these medications relief the pain? } \\
\hline Yes & $54(71.1)$ & $211(79.6)$ & $72(57.1)$ & 0.0001 \\
\hline Partially & $19(25.0)$ & $52(19.6)$ & $49(38.9)$ & 0.0001 \\
\hline No & $3(4.0)$ & $2(0.8)$ & $5(4.0)$ & 0.0001 \\
\hline Per attack: two & $29(25.2)$ & $81(24.8)$ & $71(40.1)$ & 0.0033 \\
\hline Tablets per month, number (range) ${ }^{\mathrm{a}}$ & $11.3(1.6-20.1)$ & $5.9(3.0-8.9)$ & $6.6(3.7-9.6)$ & 0.2689 \\
\hline \multicolumn{5}{|l|}{ Do these medications relief pain? } \\
\hline Yes & $12(48.0)$ & $56(78.9)$ & $31(52.5)$ & 0.0041 \\
\hline Partially & $9(36.0)$ & $14(19.7)$ & $23(39.0)$ & 0.0041 \\
\hline No & $3(12.0)$ & $1(1.4)$ & $5(8.5)$ & 0.0041 \\
\hline Per attack: three & $11(9.6)$ & $15(4.6)$ & $20(11.3)$ & 0.0033 \\
\hline Tablets per month, number (range) ${ }^{\mathrm{a}}$ & $20.1(0-45.2)$ & $13.5(0-31.1)$ & $9.4(0-21.1)$ & 0.6348 \\
\hline \multicolumn{5}{|l|}{ Do these medications relief pain? } \\
\hline Yes & $5(55.6)$ & $10(71.4)$ & $10(58.8)$ & 0.5195 \\
\hline Partially & $3(33.3)$ & $4(28.6)$ & $6(35.3)$ & 0.5195 \\
\hline No & $1(11.1)$ & 0 & $1(5.9)$ & 0.5195 \\
\hline Prophylactic treatment & $16(13.9)$ & $4(1.2)$ & $12(6.9)$ & $<0.0001$ \\
\hline \multicolumn{5}{|l|}{ Alternative methods of treatment } \\
\hline Chiropractics & $3(2.6)$ & $13(4.0)$ & $12(6.9)$ & 0.1777 \\
\hline Acupuncture & $10(8.7)$ & $11(3.4)$ & $8(4.6)$ & 0.0673 \\
\hline Homeopathy & $2(1.7)$ & $4(1.2)$ & $2(1.2)$ & 0.8964 \\
\hline Physical therapy & $11(9.6)$ & $40(12.2)$ & $17(9.8)$ & 0.6023 \\
\hline Autogenic training & $4(3.5)$ & $4(1.2)$ & $4(2.3)$ & 0.2980 \\
\hline Yoga, meditation & $8(7.0)$ & $11(3.4)$ & $9(5.2)$ & 0.2528 \\
\hline Something else & $10(8.7)$ & $40(12.2)$ & $26(14.9)$ & 0.3794 \\
\hline Total & $31(27.0)$ & $89(27.2)$ & $49(28.2)$ & 0.9670 \\
\hline \multicolumn{5}{|l|}{ Do these methods help? } \\
\hline Yes & $12(38.7)$ & $53(59.5)$ & $20(40.8)$ & 0.5446 \\
\hline Partially & $3(9.7)$ & $2(2.2)$ & $2(4.1)$ & 0.5446 \\
\hline No & $16(51.6)$ & $34(38.2)$ & $27(55.1)$ & 0.5446 \\
\hline
\end{tabular}

${ }^{a}$ Numbers represent average (range) consumption of tablets per month

Many M sufferers who do consult physicians for $\mathrm{M}$ relief do not receive a correct diagnosis. In a US study, $40 \%$ of M sufferers stated that they had not been diagnosed as having $\mathrm{M}$ even after consultation with a physician [12]. Only $45 \%$ of migraineurs who sought medical treatment for their migraines were correctly diagnosed [23]. 
Table 3 Satisfaction with current therapy (on the whole)

\begin{tabular}{lllll}
\hline Satisfaction with current therapy & $\begin{array}{l}\text { Migraine } \\
n=115(\%)\end{array}$ & $\begin{array}{l}\text { TTH } \\
n=327(\%)\end{array}$ & $\begin{array}{l}\text { PM } \\
n=174(\%)\end{array}$ & $P$ value \\
\hline Totally & $24(26.1)$ & $57(27.9)$ & $25(19.2)$ & 0.65 \\
Partially & $40(43.5)$ & $91(44.6)$ & $62(47.7)$ & 0.65 \\
Mostly not & $18(19.6)$ & $40(19.6)$ & $31(23.9)$ & 0.65 \\
Not at all & $10(10.9)$ & $16(7.8)$ & $12(9.2)$ & 0.65 \\
\hline
\end{tabular}

\begin{tabular}{llcll}
\hline Sources of health information & $\begin{array}{l}\text { Migraine } \\
n=115(\%)\end{array}$ & $\begin{array}{l}\text { TTH } \\
n=327(\%)\end{array}$ & $\begin{array}{l}\text { PM } \\
n=174(\%)\end{array}$ & $P$ value \\
\hline Primary care physician & $56(48.7)$ & $129(39.5)$ & $86(49.4)$ & 0.0535 \\
Specialist (neurologist and internal medicine) & $21(18.3)$ & $25(7.7)$ & $23(13.2)$ & 0.0049 \\
Family friends & $28(24.4)$ & $123(37.6)$ & $55(31.6)$ & 0.0288 \\
Journals & $38(33.0)$ & $181(55.4)$ & $78(44.8)$ & 0.0001 \\
TV and radio & $34(29.6)$ & $155(47.4)$ & $61(35.1)$ & 0.0008 \\
Internet & $24(20.9)$ & $36(11.0)$ & $37(21.3)$ & 0.0027 \\
Medical books & $27(23.5)$ & $50(15.3)$ & $51(29.3)$ & 0.0008 \\
None & $1(0.9)$ & $4(1.2)$ & 0 & 0.3471 \\
Other & $8(7.0)$ & $4(1.2)$ & $6(3.5)$ & 0.0064 \\
\hline
\end{tabular}

Table 4 Sources of health information reimbursed ("list A") and for others (sumatriptan nasal spray, zolmitriptan, and rizatriptan melting disks or tablets"list B") there is an additional surcharge of approximately 3-8 Euros per package. A prescription for triptans, however, is not necessary, but at a cost of between 9 and 31 Euros per package, the costs for triptans are high. The average salary in Croatia is approximately 730 Euros, and the unemployment rate is now $14 \%$. Therefore, if the patient does not have the "additional health insurance" the costs for visits to a neurologist and for triptans are rather high.

\section{Satisfaction with treatment}

One study showed that the main reasons were dissatisfaction with treatment or feeling that the physician was ignorant about, or not interested in solving the problem [10]. In a population-based study in the United States, only $29 \%$ of M sufferers reported that they were "very satisfied" with their usual acute treatment [24].

Our study showed that when specifically asked for satisfaction with treatment so far, the results of the proportion of patients in each group was similar: one-fifth to one quarter of patients being completely satisfied, nearly half of patients stated that they were partially satisfied, and approximately $30 \%$ were mostly or completely unsatisfied. Patients attending headache clinics were more satisfied with treatments provided than patients visiting community care physicians [25]. 
These data should be analyzed for use in future studies to show subgroups of patients and their reasons for dissatisfaction with current therapies. Targeting untreated groups will help establish better health care plans in Croatia. Our study has shown that the main information source are mass media (journals $55.4 \%$ and $\mathrm{TV}$ or radio $47.4 \%$ ), whereas information from the internet and from medical books is still restricted to a smaller number of health seekers.

\section{Use of acute treatment}

Triptans are widely recommended for $\mathrm{M}$ since studies have shown that their use increases productivity at work and improves the quality of life of M sufferers [26]. However, studies worldwide show that the majority of $\mathrm{M}$ patients are using OTCs and the minority is using triptans [2-6, 17, 27, 28]. This is largely influenced by the physician who is treating the patient. A study from Singapore showed that community care physicians treat patients with triptans far less than do physicians in headache clinics [25].

In our study, $57.4 \%$ of $\mathrm{M}$ patients stated that they are currently using or have tried specific $\mathrm{M}$ treatment: $35.7 \%$ used triptans and $21.8 \%$ used ergotamines or dihydroergotamines. According to Croatian guidelines for headache treatment [29], analgesics and triptans should be the first line for $\mathrm{M}$ treatment, while ergotamines can be recommended with some exceptions. However, our results show that a large number of patients are still using ergotamines. Reasons for this are probably due to the fact that these drugs were previously used as specific treatment, and patients have a lack of information regarding new drugs such as triptans. Another reason is that ergotamines are somewhat less expensive as compared to triptans: a price for 20 tablets of combined ergotamine with paracetamol and caffeine is 7 Euros; however, they are not available as OTC drugs and are not a prescription drug in Croatia (they can only be purchased abroad). The least expensive are NSAIDs; the price varies between 1 and 3 Euros for ten tablets.

In our study, $67.4 \%$ of $\mathrm{M}$ patients were satisfied with specific medications if taken on time and only $4.7 \%$ were not satisfied. Studies showed that intra-individual consistency to oral triptan response is $40-50 \%$ in $3 / 3 \mathrm{M}$ attacks [30]. Efficacy, adverse events, costs, and physician's knowledge have a major influence on triptan consumption.

Results of our study showed that patients with $\mathrm{M}$ were taking significantly more tablets per month for $\mathrm{M}$ attacks as compared with TTH patients. In the group of patients who were taking one tablet per month, $71.1 \%$ of $\mathrm{M}$ patients were satisfied with their treatment and an additional $25 \%$ were partially satisfied, whereas the percentage of satisfied patients who must take two or three medications was 48 and $55.6 \%$ respectively. In the TTH group, approximately $70-80 \%$ of all patients (taking 1, 2 or 3 tablets per attack) were satisfied with treatment. These results indicate that the more medications the patients must take per headache attack, the less likely they are to be satisfied with their efficacy. This study was not designed to provide data on medication overuse in the general population; therefore, these data is not available. A study from the USA showed that half of the patients use OTC drugs for the acute M attack despite the fact that $73 \%$ of them require a second dose or product; patients using a triptan were less likely to require a second dose or product [31]. A survey comparing the consumption of analgesics over the past 20 years in nine countries showed that in half of countries analyzed the consumption of analgesics has increased significantly, and it has remained constant or showed a minor increase in the others [32].

\section{Use of prophylactic treatment}

In our study, $13.9 \%$ of patients have used prophylactic therapy for $\mathrm{M}$. The details regarding the type and duration of prophylactic therapy were not obtained. A French study showed that only $6 \%$ of $\mathrm{M}$ patients are currently taking prophylaxis, among those $22 \%$ were in MIDAS III or IV group [3]. Another population-based study in France showed that only $0.3 \%$ of M patients and $1.4 \%$ with PM are taking prophylactic treatment [27]. A study from the USA showed that $12.4 \%$ of patients with $\mathrm{M}$ are taking prophylaxis [8] and $7.9 \%$ of PM patients, even though this percentage should be higher based on patients' characteristics [33]. In Australia, 8.3\% of patients were taking prophylactic medication [34]. In a Canadian study, only $31 \%$ of patients with severe or chronic $\mathrm{M}$ were taking prophylactic treatment [7]. More than half of patients on prophylaxis, especially $<40$ years of age, tend to discontinue the therapy within 3 months [35].

\section{Use of alternative treatment}

Alternative methods of treatment in our study have been used by approximately one quarter of patients in all three groups of patients. Approximately $40 \%$ of patients with M and PM were satisfied with alternative methods, whereas in the TTH group this percentage was even higher, at $60 \%$. Studies from other countries show that patients relatively frequently reach for alternative methods for headache treatment: approximately one-third of patients in Italy, Switzerland, and Singapore tried at least one method [25, 36, 37]. Analysis of patients who visited a specialized headache clinic revealed that even $84 \%$ tried one or more alternative methods and $60 \%$ of those stated that these methods were efficient [38]. American studies observed an 
increase in the proportion of patients seeking alternative methods for headache treatment [39].

\section{Study limitations}

This study has several limitations. First, the data were collected by a questionnaire; it is possible that the data obtained from a face-to-face interview would, to some extent, be different. Second, the data regarding the number of specific acute M treatment and OTC drugs were provided as a total number of used medication and not in separate groups. Furthermore, details about types of prophylactic treatments were not provided due to the limited number of questions asked. Finally, due to a rather small sample size our results need to be further validated.

\section{Conclusion}

Health care systems must aim to satisfactorily manage the majority of M patients by primary care physicians [21], and more severe cases should have easy access to neurologists, preferably headache specialists. Results of our study regarding treatment patterns of primary headaches in Croatia are similar to other countries worldwide, with certain differences. Current health care laws in Croatia probably influence the treatment of $\mathrm{M}$ sufferers. We believe that current health care policies in Croatia regarding headache management should be revised to offer an easier approach; patients with headache should be encouraged to visit physicians more regularly, and public information should be more accessible. Such activities are under way, and in near future we expect improvement in headache care in Croatia. We hope that the results of our study will help to improve the management of primary headaches in Croatia.

Conflict of interest None.

\section{References}

1. De Diego EV, Lanteri-Minet M (2005) Recognition and management of migraine in primary care: influence of functional impact measured by the headache impact test (HIT). Cephalalgia 25:184-190

2. Linde M, Dahlof C (2004) Attitudes and burden of disease among self-considered migraineurs-a nation-wide population-based survey in Sweden. Cephalalgia 24:455-465

3. Lucas C, Chaffaut C, Artaz MA, Lantéri-Minet M (2005) FRAMIG 2000: medical and therapeutic management of migraine in France. Cephalalgia 25:267-279

4. MacGregor EA, Brandes J, Eikermann A (2003) Migraine prevalence and treatment patterns: the global migraine and zolmitriptan evaluation survey. Headache 43:19-26
5. Lucas C, Auray JP, Gaudin AF et al (2004) Use and misuse of triptans in France: data from the GRIM2000 population survey. Cephalalgia 24:197-205

6. Lohman JJ, van der Kuy-de Ree MM, on behalf of the Group of Co-operating Pharmacists Sittard-Geleen and its environs (2005) Patterns of specific antimigraine drug use-a study based on the records of 18 community pharmacies. Cephalalgia 25:214-218

7. Jelinski SE, Becker WJ, Christie SN, Giammarco R, Mackie GF, Gawel MJ et al (2006) Clinical features and pharmacological treatment of migraine patients referred to headache specialists in Canada. Cephalalgia 26:578-588

8. Diamond S, Bigal ME, Silberstein S, Loder E, Reed M, Lipton RB (2007) Patterns of diagnosis and acute and preventive treatment for migraine in the United States: results from the American Migraine Prevalence and Prevention Study. Headache 47:355363

9. Headache Society (2004) The international classification of headache disorders. Cephalalgia 24(Suppl 1):1-160

10. Micieli G (1993) Suffering in silence. In: Edmeads J (ed) Migraine: a brighter future. Cambridge Medical Publications, Worthing, pp 1-7

11. Edmeads J, Findlay H, Tugwell P, Pryse-Phyllips W, Nelson RF, Murray TJ (1993) Impact of migraine and tension-type headache on life-style, consulting behavior, and medication use: a Canadian population survey. Can J Neurol Sci 20:131-137

12. Lipton RB, Stewart WF, Simon D (1998) Medical consultation for migraine: results from the American Study. Headache 38:8796

13. Lipton RB, Stewart WF, Liberman J (1999) Patterns of healthcare utilization for migraine in England. Cephalalgia 19:305

14. Lipton RB, Scher AI, Steiner TJ et al (2003) Patterns of health care utilization for migraine in England and in the United States. Neurology 60:441-448

15. Rasmussen BK, Jensen R, Olesen J (1992) Impact of headache on sickness absence and utilization of medical services: a Danish population study. J Epidemiol Community Health 46:443-446

16. Dahlöf C, Linde M (2001) One-year prevalence of migraine in Sweden: a population-based study in adults. Cephalalgia 21:664671

17. Takeshima T, Ishizaki K, Fukuhara Y et al (2004) Populationbased door-to-door survey of migraine in Japan: the Daisen study. Headache 44:8-19

18. Lampl C, Buzath A, Baumhackl U, Klingler D (2003) One-year prevalence of migraine in Austria: a nation-wide survey. Cephalalgia 23:280-286

19. Russell MB, Olesen J (1996) Migrainous disorder and its relation to migraine without aura and migraine with aura. A genetic epidemiologic study. Cephalalgia 16:431-435

20. Morillo LE, Alarcon F, Aranaga N et al (2005) Prevalence of migraine in Latin America. Headache 45:106-117

21. Holmes W, Laughey W, MacGregor AE et al (1999) Headache consultation and referral patterns in one UK general practice. Cephalalgia 19:328-329

22. Van Roijen L, Essink-Bot ML, Koopmanschap MA, Michel BC, Rutten FF (1995) Societal perspective on the burden of migraine in the Netherlands. Pharmacoeconomics 7:170-179

23. Stang PE, Von Korff M (1994) The diagnosis of headache in primary care: factors in the agreement of clinical and standardized diagnoses. Headache 34:138-142

24. Lipton RB, Stewart WF (1999) Acute migraine therapy: do doctors understand what patients with migraine want from therapy. Headache 39(Suppl 2):20-26

25. Soon YY, Siow HC, Tan CY (2005) Assessment of migraineurs referred to a specialist headache clinic in Singapore: diagnosis, treatment strategies, outcomes, knowledge of migraine treatments and satisfaction. Cephalalgia 25:1122-1132 
26. Dahlöf C, Bouchard J, Cortelli P, Heywood J, Jansen JP, Pham S et al (1997) A multinational investigation of the impact of subcutaneous sumatriptan. II Health-related quality of life. Pharmacoeconomics 11(Suppl 1):24-34

27. Lantéri-Minet M, Valade D, Géraud G, Chautard MH, Lucas C (2005) Migraine and probable migraine-results of FRAMIG 3, a French nationwide survey carried out according to the 2004 IHS classification. Cephalalgia 25:1146-1158

28. Panconesi A, Pavone E, Vacca F, Vaiani M, Banfi R (2008) Triptans in Italian population: a drug utilization study and a literature review. J Headache Pain 9:71-76

29. Demarin V, Vuković V, Lovrenčić-Huzjan A, Lušić I, Jančuljak D, Wilheim K et al (2005) Evidence based guidelines for treatment of primary headaches. Report of the Croatian Neurovascular Society. Acta Clin Croat 44:139-183

30. Ferrari MD, Goadsby PJ, Roon KI, Lipton RB (2002) Triptans (serotonin, 5-HT1B/1D agonists) in migraine: detailed results and methods of meta-analysis of 53 trials. Cephalalgia 22:633-658

31. MacGregor EA, Brandes J, Gendolla A, Gianmarco R (2004) Migraine treatment strategies: the global Migraine and Zolmitriptan Evaluation (MAZE) survey-phase IV. Curr Med Res Opin 20:1777-1783

32. Diener HC, Schneider R, Aicher B (2008) Per-capita consumption of analgesics: a nine-country survey over 20 years. J Headache Pain 9:225-231
33. Silberstein S, Loder E, Diamond S, Reed ML, Lipton RB, AMPP Advisory Group (2007) Probable migraine in the United States: results of the American Migraine and Prevention (AMPP) study. Cephalalgia 27:220-234

34. Stark RJ, Valenti L, Miller GC (2007) Management of migraine in Australian general practice. Med J Aust 187:142-146

35. Rahimtoola H, Buurma H, Tijssen CC, Leufkens HG, Egberts ACG (2003) Migraine prophylactic medication usage patterns in the Netherlands. Cephalalgia 23:293-301

36. Rossi P, Lorenzo MG, Faroni J, Cesarino F, Di Lorenzo C, Nappi G (2005) Prevalence, pattern and predictors of use of complementary and alternative medicine (CAM) in migraine patients attending a headache clinic in Italy. Cephalalgia 25:493-506

37. Gantenbein AR, Kozak S, Agosti F, Agosti R, Isler H (2006) Headache patients in primary care and tertiary care unit in Zürich, Switzerland. Cephalalgia 26:1451-1457

38. von Peter S, Ting W, Scrivani S, Korkin E, Okvat H, Gross M et al (2002) Survey on the use of complementary and alternative medicine among patients with headache syndromes. Cephalalgia 22:395-400

39. Eisenberg DM, Davis SL, Ettner S, Appel S, Wilkey S, van Rompany M et al (1998) Trends in alternative medicine use in the United States, 1990-97. JAMA 280:1569-1575 